\title{
Pseudolymphoma of the liver: a case report and literature review
}

\author{
Kazuhiro Taguchi ${ }^{1}$, Shintaro Kuroda ${ }^{1 *}$, Tsuyoshi Kobayashi ${ }^{1}$, Hirotaka Tashiro ${ }^{1}$, Kohei Ishiyama ${ }^{1}$, Kentaro Ide ${ }^{1}$, \\ Masahiro Ohira ${ }^{1}$, Hiroyuki Tahara', Koji Arihiro ${ }^{2}$ and Hideki Ohdan ${ }^{1}$
}

\begin{abstract}
Pseudolymphoma is a benign lymphocytic tumor-like lesion, and its occurrence in the liver is rare. Here, we report the case of a 78-year-old woman with pseudolymphoma of the liver. She had a history of tremors for several years. Therefore, she underwent computed tomography (CT) for screening, and liver tumors were incidentally identified. She did not have any history of liver disease. Liver function test results and tumor marker levels were all within normal limits, and viral markers for hepatitis were negative. Contrast-enhanced CT revealed four nodules measuring up to $13 \mathrm{~mm}$ in diameter with ring enhancement in both lobes of the liver. On magnetic resonance imaging, the lesions showed slightly high intensity on T2-weighted images and high intensity on diffusion-weighted images. Because of atypical imaging findings, the tumors could not be definitively diagnosed. Therefore, we performed laparoscopic limited resection of segments 2, 3, 4, and 8 of the liver. The final pathological diagnosis was pseudolymphoma of the liver. The patient has had no signs of recurrence for 6 months after the surgery. Although pseudolymphoma of the liver is rare, it is necessary to consider it in the differential diagnosis of a liver tumor.
\end{abstract}

Keywords: Pseudolymphoma; Liver; Laparoscopic hepatectomy

\section{Background}

Pseudolymphoma or reactive lymphoid hyperplasia is a benign nonspecific lesion characterized by a marked proliferation of polyclonal lymphocytes forming follicles with an active germinal center [1,2]. Although pseudolymphoma has been reported in various organs, including the skin [3], lungs [4, 5], eye orbit [6], intestine [7-9], and thyroid [10], its occurrence in the liver is rare. The etiology of pseudolymphoma is yet unknown, and it has been speculated to represent a reactive immunological response to a chronic infection or inflammatory process [11]. In addition, its association with malignancy has been reported [2]. The preoperative diagnosis of pseudolymphoma is difficult because the imaging findings are usually equivocal. Herein, we report the case of a patient with pseudolymphoma of the liver.

\footnotetext{
* Correspondence: df26@smn.enjoy.ne.jp

${ }^{1}$ Department of Gastroenterological and Transplant Surgery, Hiroshima University Hospital, 1-2-3 Kasumi Minami ward, Hiroshima 734-8551, Japan Full list of author information is available at the end of the article
}

\section{Case presentation}

A 78-year-old woman with a history of tremors for several years presented to the Department of Neurology in our hospital. She was admitted to our hospital, and she underwent computed tomography $(\mathrm{CT})$ for screening. The CT scan incidentally revealed multiple lesions in the liver; therefore, a qualitative diagnosis was required.

The results of laboratory examinations, including liver function tests, were all within normal limits. The results were as follows: white blood cell count, $6940 / \mathrm{mm}^{3}$; hemoglobin level, $14.1 \mathrm{~g} / \mathrm{dL}$; platelet count, $20.8 \times 10^{4} /$ $\mathrm{mm}^{3}$; serum aspartate aminotransferase level, $21 \mathrm{IU} / \mathrm{L}$; serum alanine aminotransferase level, $19 \mathrm{IU} / \mathrm{L}$; alkaline phosphatase level, $204 \mathrm{IU} / \mathrm{L} ; \gamma$-glutamyl transpeptidase level, $37 \mathrm{IU} / \mathrm{L}$; and total bilirubin level, $1.0 \mathrm{mg} / \mathrm{dL}$. The levels of tumor markers, including alpha-fetoprotein, a protein induced by vitamin $\mathrm{K}$ absence, carcinoembryonic antigen, carbohydrate antigen 19-9, and soluble interleukin-2 receptor, were all within normal limits. Viral markers for hepatitis $B$ and $C$ were negative. Levels of immunoglobulin (Ig) G, including IgG4, IgA, and IgM were normal. Tests

\section{Springer}

(C) 2015 Taguchi et al. Open Access This article is distributed under the terms of the Creative Commons Attribution 4.0 International License (http://creativecommons.org/licenses/by/4.0/), which permits unrestricted use, distribution, and reproduction in any medium, provided you give appropriate credit to the original author(s) and the source, provide a link to the Creative Commons license, and indicate if changes were made. 
for antinuclear antibody, anti-DNA antibody, and antismooth muscle antibody were negative.

Imaging revealed four nodules measuring up to $13 \mathrm{~mm}$ in diameter in segments $2,3,4$, and 8 of the liver. Ultrasonography revealed low echoic lesions in segments 2 (13 $\mathrm{mm}$ in diameter) and 3 ( $8 \mathrm{~mm}$ in diameter) of the liver. On contrast-enhanced ultrasonography using perflubutane, these lesions showed enhancement in the arterial phase, subsequent washout in the portal phase, and defects in the Kupffer phase. On contrast-enhanced CT, these nodules showed ring enhancement in the arterial phase and subsequent washout in the portal phase. In addition, small nodules with the same enhancement pattern were identified in segments 4 and 8 (Fig. 1). CT arterial portography revealed nodular perfusion defects, and CT hepatic arteriography revealed strong enhancement in the early phase and ring enhancement in the late phase. Magnetic resonance imaging (MRI) showed low intensity on T1 weighted images, slightly high intensity on T2 weighted images, and high intensity on diffusion-weighted images. On gadolinium-ethoxybenzyl-diethylenetriamine pentaacetic acid (Gd-EOB-DTPA)-enhanced dynamic MRI, the nodules showed ring enhancement in the arterial phase and defects in the hepatocyte phase (Fig. 2). The patient also underwent whole-body positron emission tomography-computed tomography, and all lesions had standardized uptake values up to 4.6.

Because of atypical imaging findings, these tumors could not be definitively diagnosed. The differential diagnosis included hepatocellular carcinoma (HCC), metastatic liver tumor (unknown primary origin), malignant lymphoma, inflammatory pseudotumor, and pseudolymphoma. We performed laparoscopic limited resection of segments 2, 3, 4 , and 8 of the liver.

On visual examination of the resected liver specimens, the tumors appeared well circumscribed and ash colored (Fig. 3). On histopathological examination of the tumors, many aggregated lymphoid follicles were noted with germinal centers consisting of lymphocytic or plasmacytic cells without atypia along with fibrocollagenous and hyalinized stroma. The lymphoid follicles varied in size and shape, and the germinal centers included small or large lymphoid cells and tingible body macrophages. On immunohistochemical examination of the tumors, CD3positive cells were mainly localized in the parafollicular area, and CD20 and 79a immunostaining was positive in $\mathrm{B}$ follicles, while Bcl-2 staining was negative (Fig. 4). Thus, the possibility of well-defined follicular lymphoma was excluded, and pseudolymphoma of the liver was finally diagnosed. The patient has had no signs of recurrence for 6 months after the surgery.

\section{Discussion}

We reported the case of a patient with pseudolymphoma of the liver. Pseudolymphoma is a nodular lesion considered to result from a reactive immunological response; however, the etiology of pseudolymphoma is yet unknown [1]. It was first described in the lungs by Saltzstein et al. in 1963 as a lymphocytic tumor associated with inflammation and with no evidence of systemic dissemination [12]. Pseudolymphoma of the liver is rare and was first reported by Snover et al. in 1981 [13]. Pseudolymphoma is defined histologically as the aggregation of lymphoid follicles typically with reactive

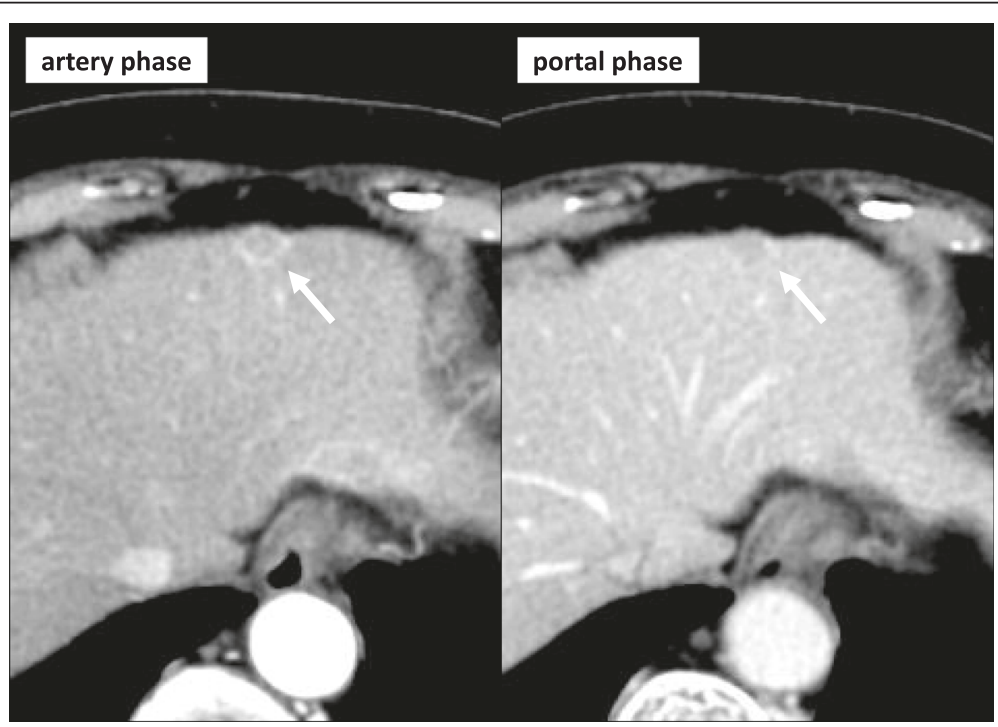

Fig. 1 Contrast-enhanced computed tomography showing a nodule with ring enhancement in the arterial phase and subsequent washout in the portal phase in segments 2, 3 (arrow), 4, and 8 of the liver 


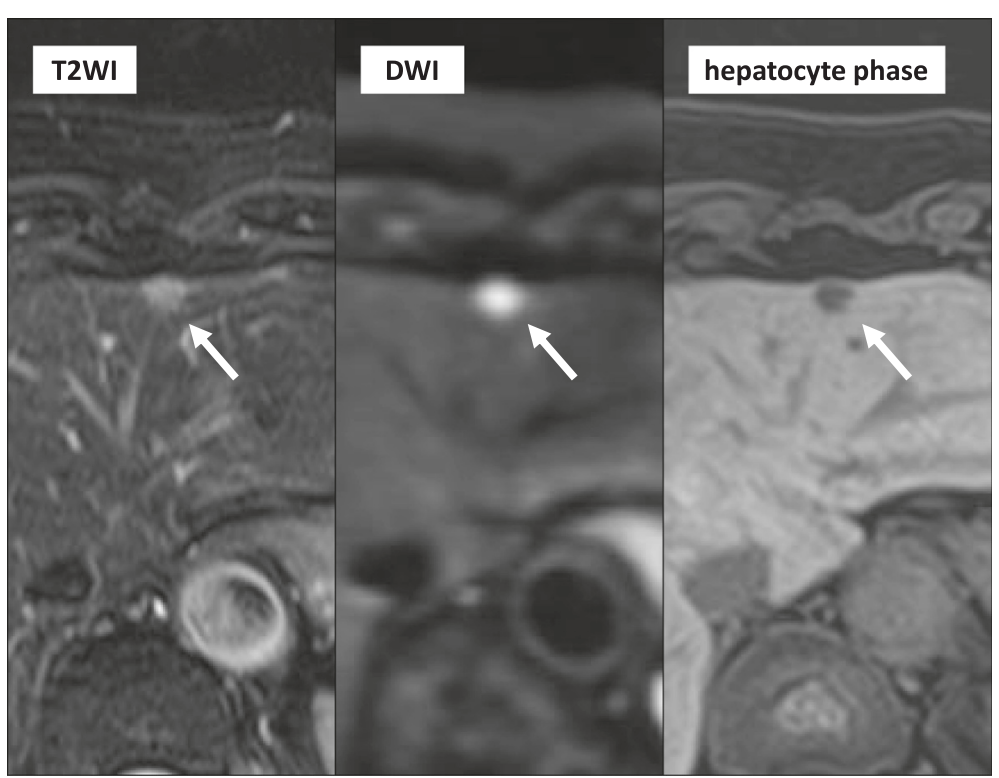

Fig. 2 Magnetic resonance imaging (MRI) showing a nodule with slight high intensity on a T2-weighted image and high intensity on a diffusionweighted image. Gadolinium-ethoxybenzyl-diethylenetriamine pentaacetic acid-enhanced dynamic MRI showing a nodule with defects in the hepatocyte phase in segments 2, 3 (arrow), 4, and 8 of the liver

hyperplasia of germinal centers showing proliferation of polyclonal lymphocytes without atypia.

We reviewed the PubMed database from 1985 to 2014, using the keywords "liver," "pseudolymphoma," and "lymphoid hyperplasia," and we found 50 cases of pseudolymphoma of the liver. These cases and our case are summarized in Table 1 . The mean age of the patients was 58.9 years (range, 27-85; median, 60). Of the 51 cases, 5 (9.8\%) involved male patients and 46 involved female patients (90.2\%). Among the 51 cases, 14 (27.4\%) had malignant diseases, including gastric cancer [14-17], colon cancer [2, 18, 19], uterine/ovarian cancer [20], renal cell carcinoma [21, 22], pancreatic cancer [17], common bile duct cancer [23], and HCC [24]. Therefore, the pathogenesis of pseudolymphoma of the liver with an associated malignant tumor may be related to an immunological abnormality caused by the malignant tumor itself. However, we cannot confirm the
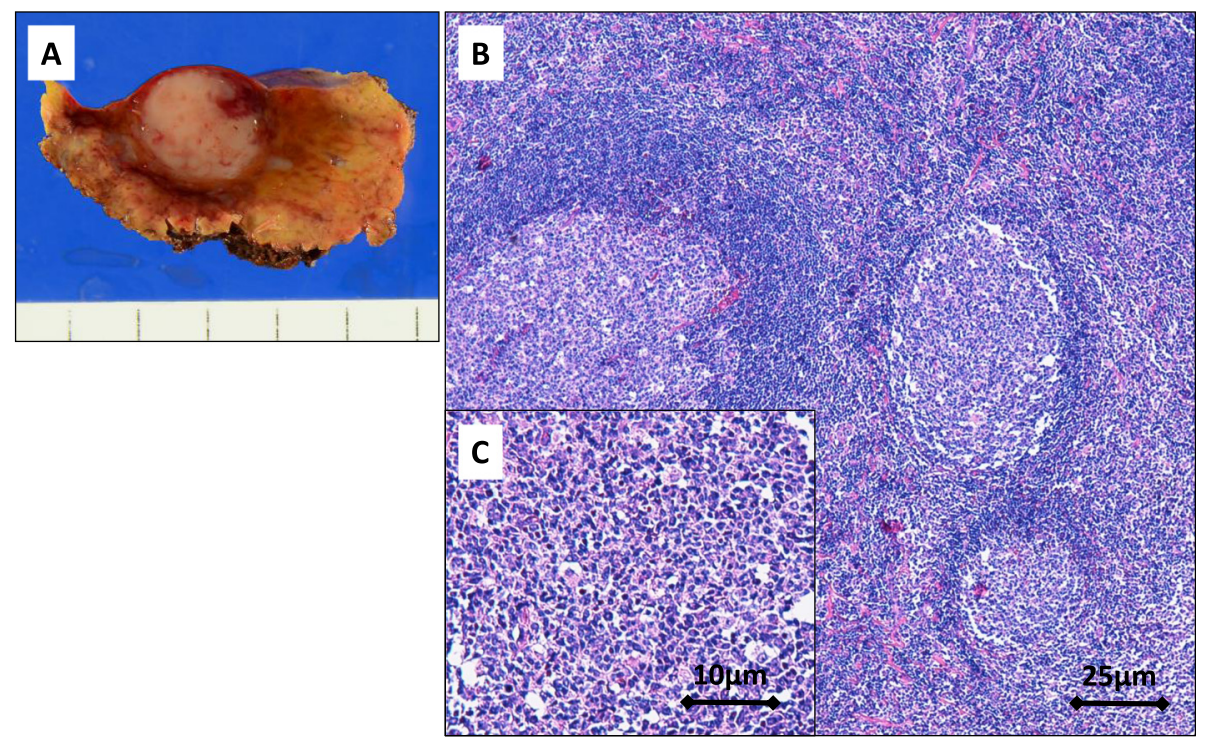

Fig. 3 Image of a resected liver specimen showing a well-circumscribed, ash-colored tumor (a). On histological analysis, many aggregated lymphoid follicles are seen with germinal centers consisting of lymphocytic or plasmacytic cells without atypia (b: scale bar, $25 \mu \mathrm{m}, \mathbf{c}$ : scale bar $10 \mu \mathrm{m}$ ) 


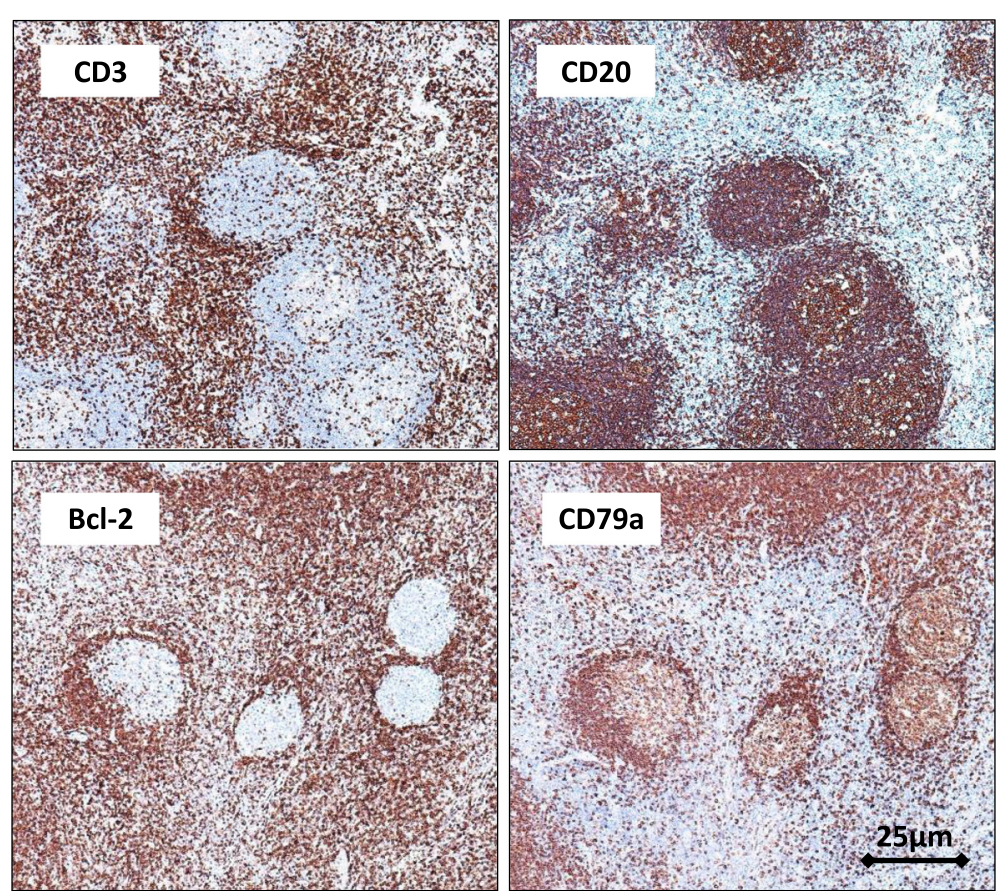

Fig. 4 Immunohistochemical analysis of the tumor. CD3-positive cells are mainly localized in the parafollicular area, and CD20 and CD79a immunostaining is positive in B follicles, while Bcl-2 staining is negative (scale bar, $25 \mu \mathrm{m}$ )

relationship between the presence of a pseudolymphoma of the liver and a malignant tumor. This association may be found frequently on incidental image examinations in patients with malignant diseases.

Because pseudolymphoma is a lymphoid reaction, it has been suggested that immunological dysregulation is associated with pseudolymphoma [24]. Among the 51 cases reviewed, 11 (22.2 \%) had extrahepatic autoimmune diseases, including Sjogren's syndrome in 4 cases $[25,26]$, autoimmune thyroiditis in 4 cases [24, 27-29], Takayasu aortitis in 1 case [24], antiphospholipid syndrome in 1 case, and CREST syndrome (limited cutaneous form of systemic scleroderma) in 1 case [1]. However, the present patient did not have any autoimmune disease.

Among the 51 cases reviewed, 14 (27.5\%) had chronic liver diseases, including primary biliary cirrhosis in 6 cases $[1,16,24,26,30]$, viral hepatitis in 6 cases $[24,31$, 32], and nonalcoholic steatohepatitis in 2 cases [33, 34]. Pseudolymphoma has been reported to develop after interferon treatment for chronic hepatitis [31, 35]. This finding supports the inflammatory nature of the lesion. Moreover, lymphoid follicles are generally not identified in the portal area of a normal liver but are found in a liver with chronic hepatitis. Therefore, pseudolymphoma of the liver has been reported to be associated with hepatitis [24, 32]. However, the present patient did not have any liver disease, including chronic hepatitis.

Imaging findings of pseudolymphoma resemble those of other vascular tumors of the liver, such as HCC, cholangiocarcinoma, and metastatic liver tumor; therefore, preoperative diagnosis of pseudolymphoma of the liver is extremely difficult with imaging studies alone. In terms of preoperative imaging findings, it has been reported that most pseudolymphomas appear as low echoic lesions with or without well-defined margins on ultrasonography and as lesions having a low density on plain CT [36]. In this case, the lesions showed defects in the Kupffer phase on contrast-enhanced ultrasonography using perflubutane. Perflubutane is phagocytosed by macrophages, including Kupffer cells. A pseudolymphoma is a non-malignant tumor and lymphoid hyperplasia, but pseudolymphoma lesions in the liver replace normal liver tissue. Therefore, these lesions have fewer macrophages, including Kupffer cells, than normal liver tissue, and these lesions may demonstrate a defect in the Kupffer phase. Additionally, the lesions have variable density on contrast $\mathrm{CT}$, and many show enhancement in the early phase and wash out in the late phase [32, 37]. On MRI, most of the lesions show low intensity on T1weighted images, high intensity on T2-weighted images, hyperintensity on diffusion-weighted images, and hypointensity on T1-weighted images in the hepatocyte phase with Gd-EOB-DTPA enhancement [37]. Pseudolymphoma of the liver may mimic a primary or metastatic hepatic malignancy radiologically, especially in patients with chronic hepatitis or internal malignancies. Among the 51 reviewed cases, 19 had been misdiagnosed with HCC preoperatively. Our patient did not have any risk 
Table 1 Clinical presentation of cases of pseudolymphoma of the liver

\begin{tabular}{|c|c|}
\hline & $N=51$ \\
\hline Age, years & $58.9(27-85)$ \\
\hline \multicolumn{2}{|l|}{ Sex } \\
\hline Male & $5(9.8 \%)$ \\
\hline Female & $46(90.2 \%)$ \\
\hline Associated cancer & $14(27.4 \%)$ \\
\hline Gastric cancer & 4 \\
\hline Colon cancer & 4 \\
\hline Uterine/ovarian cancer & $1 / 1$ \\
\hline Renal cell carcinoma & 2 \\
\hline Pancreatic cancer & 1 \\
\hline Common bile duct cancer & 1 \\
\hline $\mathrm{HCC}$ & 1 \\
\hline Associated autoimmune disease & $11(22.2 \%)$ \\
\hline Sjogren's disease & 4 \\
\hline Autoimmune thyroiditis & 4 \\
\hline Takayasu disease & 1 \\
\hline Antiphospholipid syndrome & 1 \\
\hline CREST syndrome & 1 \\
\hline Associated liver disease & $14(27.5 \%)$ \\
\hline PBC & 6 \\
\hline Chronic viral hepatitis & 6 \\
\hline $\mathrm{NASH}$ & 2 \\
\hline Preoperative diagnosis & 41 (described) \\
\hline $\mathrm{HCC}$ & 19 \\
\hline Metastatic liver tumor & 13 \\
\hline CCC & 4 \\
\hline Pseudolymphoma & 3 \\
\hline Others & 2 \\
\hline
\end{tabular}

Data are presented as mean (range), number (percentage), or number $H C C$ hepatocellular carcinoma, PBC primary biliary cirrhosis, NASH nonalcoholic steatohepatitis, CCC cholangiocellular carcinoma

factors for HCC. Additionally, the patient's liver was not cirrhotic and the levels of tumor markers were within normal limits. However, CT and MRI revealed multiple tumors with ring enhancement. Therefore, malignancy could not be excluded. We considered hepatic biopsy; however, we believed that it would be insufficient to obtain an accurate diagnosis and there was a possibility of needle implantation of malignant tumor cells. Therefore, we decided to perform hepatectomy without biopsy.

Histologically, pseudolymphoma consists of hyperplastic lymphoid follicles, lymphocytes, and other inflammatory cells, and an accurate diagnosis of pseudolymphoma relies on immunohistochemical analysis [38]. Immunohistochemical staining shows positive results for $\mathrm{CD} 3$, CD4, and CD8 ( $\mathrm{T}$ cell markers) and CD20 and CD79a (B cell markers), indicating the polyclonality of the tumor. Additionally, CD20 positive B cells are predominantly located within the lymphoid follicles, and CD3 positive T cells are predominantly located in the peri and interfollicular areas. However, the lymphocytes within the germinal centers are negative for $\mathrm{Bcl}-2$, indicating the reactive and nonneoplastic nature of the tumor [20].

The difference between pseudolymphoma and malignant lymphoma is significant. Although the precise etiology and pathogenesis of pseudolymphoma remain unknown, its prognosis is much better than that of malignant lymphoma, especially follicular lymphoma. Follicular lymphoma includes atypical cells and shows monoclonal proliferation. Additionally, Bcl-2 expression in lymphoid follicles is distinct for follicular lymphoma. Moreover, in situ hybridization demonstrates intermixed kappa and lambda light chains within interfollicular plasma cells. DNA analysis helps to distinguish these lesions from those capable of malignant clonal lymphoproliferation by ruling out monoclonal rearrangements of immunoglobulin heavy chains or $\mathrm{T}$ cell receptor beta and gamma genes [32].

\section{Conclusions}

In conclusion, pseudolymphoma of the liver should be considered in the differential diagnosis of small hepatic tumors, especially in female patients and patients with no risk factors for hepatocellular carcinoma. Because it is difficult to preoperatively distinguish pseudolymphoma from malignant tumors and metastases on the basis of imaging findings, careful follow-up of patients is essential and surgical intervention should be the choice of treatment on suspicion of malignancy.

\section{Consent}

Consent was obtained from the patient for the publication of this case report.

\section{Abbreviations}

$C T$ : computed tomography; Gd-EOB-DTPA: gadolinium-ethoxybenzyldiethylenetriamine pentaacetic acid; HCC: hepatocellular carcinoma; MRI: magnetic resonance imaging.

\section{Competing interest}

All authors declare no conflicts of interest.

\section{Authors' contributions}

Taguchi, Kuroda, Kobayashi, and Ohdan conceived and designed the report. Ishiyama, Ide, Tahara, and Ohira participated in the acquisition of data. Taguchi, Kobayashi, Kuroda, Tashiro, Arihiro, and Ohdan analyzed and interpreted the data. Kuroda and Kobayashi helped to draft the manuscript. Kuroda, Kobayashi, and Ohdan coordinated and critically revised the report. All authors read and approved the final manuscript.

\section{Authors' information}

$\mathrm{KT}, \mathrm{MD}$, is a clinician of the Department of Gastroenterological and Transplant Surgery, Hiroshima University Hospital. SK, MD, PhD is a clinician of the Department of Gastroenterological and Transplant Surgery, Hiroshima University Hospital. TK, MD, PhD is an assistant professor of the Department of 
Gastroenterological and Transplant Surgery, Hiroshima University Hospital. HT, $\mathrm{MD}, \mathrm{PhD}$ is an associate professor of the Department of Gastroenterological and Transplant Surgery, Hiroshima University Hospital. Kl, MD, PhD is an assistant professor of the Department of Gastroenterological and Transplant Surgery, Hiroshima University Hospital. Kl, MD, PhD is an assistant professor of the Department of Gastroenterological and Transplant Surgery, Hiroshima University Hospital. MO, MD, PhD is an assistant professor of the Department of Gastroenterological and Transplant Surgery, Hiroshima University Hospital. HT, MD, PhD is a clinician of the Department of Gastroenterological and Transplant Surgery, Hiroshima University Hospital. KA, MD, PhD is a professor of the Department of Anatomical Pathology, Hiroshima University Hospital. HO, MD, $\mathrm{PhD}$ is a professor of the Department of Gastroenterological and Transplant Surgery, Hiroshima University Hospital.

\section{Author details}

'Department of Gastroenterological and Transplant Surgery, Hiroshima University Hospital, 1-2-3 Kasumi Minami ward, Hiroshima 734-8551, Japan. ${ }^{2}$ Department of Anatomical Pathology, Hiroshima University Hospital, 1-2-3 Kasumi Minami ward, Hiroshima 734-8551, Japan.

\section{Received: 15 August 2015 Accepted: 14 October 2015}

\section{Published online: 17 October 2015}

\section{References}

1. Sharifi S, Murphy M, Loda M, Pinkus GS, Khettry U. Nodular lymphoid lesion of the liver: an immune-mediated disorder mimicking low-grade malignant lymphoma. Am J Surg Pathol. 1999;23:302-8.

2. Sato K, Ueda Y, Yokoi M, Hayashi K, Kosaka T, Katsuda S. Reactive lymphoid hyperplasia of the liver in a patient with multiple carcinomas: a case report and brief review. J Clin Pathol. 2006;59:990-2.

3. Arai $E$, Shimizu M, Hirose T. A review of 55 cases of cutaneous lymphoid hyperplasia: reassessment of the histopathologic findings leading to reclassification of 4 lesions as cutaneous marginal zone lymphoma and 19 as pseudolymphomatous folliculitis. Hum Pathol. 2005;36:505-11.

4. Abbondanzo SL, Rush W, Bijwaard KE, Koss MN. Nodular lymphoid hyperplasia of the lung: a clinicopathologic study of 14 cases. Am J Surg Pathol. 2000;24:587-97.

5. Saltzstein SL. Pulmonary malignant lymphomas and pseudolymphomas: classification, therapy, and prognosis. Cancer. 1963;16:928-55.

6. Knowles DM, Jakobiec FA, McNally L, Burke JS. Lymphoid hyperplasia and malignant lymphoma occurring in the ocular adnexa (orbit, conjunctiva, and eyelids): a prospective multiparametric analysis of 108 cases during 1977 to 1987. Hum Pathol. 1990;21:959-73.

7. Brooks JJ, Enterline HT. Gastric pseudolymphoma. Its three subtypes and relation to lymphoma. Cancer. 1983;51:476-86.

8. Tokunaga O, Watanabe T, Morimatsu M. Pseudolymphoma of the stomach. A clinicopathologic study of 15 cases. Cancer. 1987;59:1320-7.

9. Kojima M, Itoh H, Motegi A, Sakata N, Masawa N. Localized lymphoid hyperplasia of the rectum resembling polypoid mucosa-associated lymphoid tissue lymphoma: a report of three cases. Pathol Res Pract. 2005;201:757-61.

10. Mizukami Y, Nonomura A, Michigishi T, Noguchi M, Nakamura S, Ishizaki T. Pseudolymphoma of the thyroid gland. A case report. Pathology, research and practice. 1996; 192: 166-9; discussion 170-1.

11. Takahashi H, Sawai H, Matsuo Y, Funahashi H, Satoh M, Okada Y, et al. Reactive lymphoid hyperplasia of the liver in a patient with colon cancer: report of two cases. BMC Gastroenterol. 2006;6:25.

12. Saltzstein HC, Sandweiss DJ. Some commoner difficulties in diagnosis and treatment of carcinoma of the rectum and colon. Ann Surg. 1931;93:336-47.

13. Snover DC, Filipovich AH, Dehner LP, Krivit W. 'Pseudolymphoma'. A case associated with primary immunodeficiency disease and polyglandular failure syndrome. Arch Pathol Lab Med. 1981;105:46-9.

14. Grouls V. Pseudolymphoma (inflammatory pseudotumor) of the liver. Zentralbl Allg Pathol. 1987;133:565-8.

15. Kim SR, Hayashi Y, Kang KB, Soe CG, Kim JH, Yang MK, et al. A case of pseudolymphoma of the liver with chronic hepatitis C. J Hepatol. 1997;26:209-14.

16. Ishida M, Nakahara T, Mochizuki Y, Tsujikawa T, Andoh A, Saito Y, et al. Hepatic reactive lymphoid hyperplasia in a patient with primary biliary cirrhosis. World J Hepatol. 2010;2:387-91.
17. Yoshikawa K, Konisi M, Kinoshita T, Takahashi S, Gotohda N, Kato Y, et al. Reactive lymphoid hyperplasia of the liver: literature review and 3 case reports. Hepatogastroenterology. 2011;58:1349-53.

18. Lin E. Reactive lymphoid hyperplasia of the liver identified by FDG PET. Clin Nucl Med. 2008;33:419-20.

19. Kobayashi A, Oda T, Fukunaga K, Sasaki R, Minami M, Ohkohchi N. MR imaging of reactive lymphoid hyperplasia of the liver. J Gastrointest Surg. 2011;15:1282-5.

20. Marchetti C, Manci N, Di Maurizio M, Di Tucci C, Burratti M, luliano M, et al. Reactive lymphoid hyperplasia of liver mimicking late ovarian cancer recurrence: case report and literature review. Int J Clin Oncol. 2011;16:714-7.

21. Park HS, Jang KY, Kim YK, Cho BH, Moon WS. Histiocyte-rich reactive lymphoid hyperplasia of the liver: unusual morphologic features. J Korean Med Sci. 2008;23:156-60.

22. Osame A, Fujimitsu R, Ida M, Majima S, Takeshita M, Yoshimitsu K. Multinodular pseudolymphoma of the liver: computed tomography and magnetic resonance imaging findings. Jpn J Radiol. 2011;29:524-7.

23. Moon WS, Choi KH. Reactive lymphoid hyperplasia of the liver. Clin Mol Hepatol. 2013;19:87-91.

24. Zen Y, Fujii T, Nakanuma Y. Hepatic pseudolymphoma: a clinicopathological study of five cases and review of the literature. Mod Pathol. 2010;23:244-50.

25. Okubo H, Maekawa H, Ogawa K, Wada R, Sekigawa I, lida N, et al. Pseudolymphoma of the liver associated with Sjogren's syndrome. Scand J Rheumatol. 2001;30:117-9.

26. Sato S, Masuda T, Oikawa H, Satoh T, Suzuki Y, Takikawa Y, et al. Primary hepatic lymphoma associated with primary biliary cirrhosis. Am J Gastroenterol. 1999;94:1669-73.

27. Machida T, Takahashi T, Itoh T, Hirayama M, Morita T, Horita S. Reactive lymphoid hyperplasia of the liver: a case report and review of literature. World J Gastroenterol. 2007;13:5403-7.

28. Jiménez R, Beguiristain A, Ruiz-Montesinos I, Villar F, Medrano MA, Garnateo F, et al. Nodular lymphoid hyperplasia of the liver. Hepatic pseudolymphoma. Rev Esp Enferm Dig. 2007;99:300-1.

29. Nagano K, Fukuda Y, Nakano I, Katano Y, Toyoda H, Nonami T, et al. Reactive lymphoid hyperplasia of liver coexisting with chronic thyroiditis: radiographical characteristics of the disorder. J Gastroenterol Hepatol. 1999;14:163-7.

30. Fukuo Y, Shibuya T, Fukumura Y, Mizui T, Sai JK, Nagahara A, et al. Reactive lymphoid hyperplasia of the liver associated with primary biliary cirrhosis. Med Sci Monit. 2010;16:CS81-6.

31. Ohtsu T, Sasaki Y, Tanizaki H, Kawano N, Ryu M, Satake M, et al. Development of pseudolymphoma of liver following interferon-alpha therapy for chronic hepatitis B. Intern Med. 1994;33:18-22.

32. Amer A, Mafeld S, Saeed D, Al-Jundi W, Haugk B, Charnley R, et al. Reactive lymphoid hyperplasia of the liver and pancreas. A report of two cases and a comprehensive review of the literature. Clin Res Hepatol Gastroenterol. 2012;36:71-80.

33. Katayanagi $K$, Terada T, Nakanuma Y, Ueno T. A case of pseudolymphoma of the liver. Pathol Int. 1994;44:704-11.

34. Zen Y, Katayanagi K, Tsuneyama K, Harada K, Araki I, Nakanuma Y. Hepatocellular carcinoma arising in non-alcoholic steatohepatitis. Pathol Int. 2001;51:127-31.

35. Tanizawa T, Eishi Y, Kamiyama R, Nakahara M, Abo Y, Sumita T, et al. Reactive lymphoid hyperplasia of the liver characterized by an angiofollicular pattern mimicking Castleman's disease. Pathol Int. 1996;46:782-6.

36. Matsumoto N, Ogawa M, Kawabata M, Tohne R, Hiroi Y, Furuta T, et al. Pseudolymphoma of the liver: sonographic findings and review of the literature. J Clin Ultrasound. 2007;35:284-8.

37. Yoshida K, Kobayashi S, Matsui O, Gabata T, Sanada J, Koda W, et al. Hepatic pseudolymphoma: imaging-pathologic correlation with special reference to hemodynamic analysis. Abdom Imaging. 2013;38:1277-85.

38. Yang CT, Liu KL, Lin MC, Yuan RH. Pseudolymphoma of the liver: report of a case and review of the literature. Asian journal of surgery. 2013. doi: 10.1016/j.asjsur.2013.07.013 